\title{
POLYMERIZATION OF CYCLIC ESTERS OF PHOSPHORIC ACID
}

\author{
STANISLAW PENCZEK \\ Polish Academy of Sciences, Centre of Molecular and Macromolecular Studies, 90-362 Kódź, Poland
}

\begin{abstract}
High molecular weight polyesters of phosphoric acid, have been prepared with a sequence of atoms in the main chain similar to that in naturally occuring polymers, teichoic acid or nucleic acids.

Although the five and six-membered cyclic esters of phosphoric acid polymerize readily, such as with anionic or cationic initiation, the polymerization degrees are low because of an extensive chain transfer to monomer which competes successfully with chain propagation.

Polymerization of the six-membered esters is highly reversible. The corresponding thermodynamic equilibrium parameters have been determined for several monomers (differing in structure of the exocyclic group) and the linear isoequilibrium dependence $\left(\Delta H_{1 s}\right.$ as a function of $\left.\Delta S_{1 s}^{\circ}\right)$ has been found. For a model monomer, 2-methyl-2-oxo-1,3,2dioxaphosphorinane) the kinetics of anionic and cationic polymerization is described and the corresponding activation parameters are discussed. Structure of the polymer chain has been determined by ${ }^{1} \mathrm{H},{ }^{31} \mathrm{P}$ and ${ }^{13} \mathrm{C}-\mathrm{NMR}$ and it is shown subsequently that cyclic end-groups are present, formed in the chain transfer reaction.

In order to avoid the chain transfer, involving the exocyclic ester group, 2-hydro-2-oxo-1,3,2-dioxaphosphorinane was used as a monomer. High molecular weight polymers have been prepared and subsequently oxidized the corresponding acidic polyesters.

The five-membered 2-alkyl-2-oxo-1,3,2-dioxaphospholanes have been polymerized with organometallic initiators. The use of these initiators eliminates the chain transfer and leads to the high-molecular weight polymers $\left(\bar{M}_{n}>10^{5}\right)$. The conversion of the neutral polyesters into the acidic polyesters is described.
\end{abstract}

\section{INTRODUCTION. SIGNIFICANCE OF THE \\ POLYESTERS OF PHOSPHORIC ACID}

Studies of the polyesters of phosphoric acid of the general formula:<smiles>[R]OP(C)(=O)OCCOC</smiles>

where $n>2$ have apparently been hampered by the tacit assumption that these polymers cannot be sufficiently stable towards acid and/or base hydrolysis. However, comparison of the second order rate constants of hydrolysis measured in water with aqueous base clearly shows that the stability of the low molecular weight models of polyphosphates compares favourably with the simple esters of aliphatic carbon acids. Thus, the second order rate constant for hydrolysis of trimethylphosphate is equal to $3.4 \cdot 10^{-4} 1 \cdot \mathrm{mol}^{-1} \cdot \mathrm{sec}^{-1}$ at $35^{\circ}$, , while, for instance, for methylbenzoate this constant equals $9 \cdot 10^{-3} \mathrm{l} \cdot \mathrm{mol}^{-1} \cdot \mathrm{sec}^{-1}$.

Moreover, the hydrolytic stability in the base catalyzed reaction increases in the order: dialkyl > monoalkyl $>$ trialkyl phosphate, because a nucleophilic attack of the hydroxyl anion on the $\mathrm{P}$ atom becomes more difficult when the electrophilicity of the latter decreases: ${ }^{3}$<smiles>[R]O[PH]([R20])(=O)([O-])[O-]</smiles>

1<smiles>[R]OP(=O)([O-])O</smiles>

2
It should be remembered in these comparisons, that ions like 2 exist in solutions in equilibrium with their covalent counterparts, and, therefore, the observed rate of hydrolysis is a function of the rate constants of hydrolysis of individual compounds present in the given system, and of the equilibrium constants, governing their relative concentrations.

This relative stability is in agreement with what has been qualitatively known for many years namely, that triesters of phosphoric acid are hydrolyzed in basic solution rather readily to the corresponding diesters, but that subsequent stages of hydrolysis are relatively slow. ${ }^{1}$

The rate constant of hydrolysis of 2 with aqueous base has not been measured at room temperature; at $125^{\circ}$ in water the second order rate constant for attack at phosphorus is equal to $5 \cdot 10^{-7} \mathrm{l} \cdot \mathrm{mol}^{-1} \cdot \mathrm{sec}^{-1}$. This value shows the reasonably high hydrolytic stability of the dialkyl phosphates in the form of an anion.

This behavior of dialkylphosphates could indeed be anticipated, because the naturally occuring polymers, like nucleic acids (3) or teichoic acids (4), are perfectly stable in living organisms.

These biopolymers are built over a backbone, being a chain of polydialkylphosphate:<smiles>[B]C1COC([10BH2])C1OP(=O)([O-])O</smiles>

3

(where $\mathrm{B}=$ base)<smiles>[R]C(CC)COP(=O)([O-])O[Na]</smiles>

4

(where $\mathrm{R}=$ glucosyl or alanyl ${ }^{4}$ )

Synthetic high molecular weight polyesters of phosphoric acid have not yet been reported in the literature. 
The only information about the high molecular weight products (poly(alkyl ethylene phosphates)) comes from a patent. ${ }^{5}$

In the present paper our recent work on the polymerization of cyclic esters of phosphoric acid, leading to the linear polyesters of phosphoric acid, is described. The high molecular weight polyesters have eventually been converted into acidic polyesters with a sequence of atoms in the backbone similar to the naturally occuring polymers. These polyesters are the first representatives of the new class of polyelectrolytes prepared, although indirectly, by a ring-opening polymerization.

\section{THERMODYNAMICS OF POLYMERIZATION}

The only data on the ring strain in cyclic phosphates has been available from studies of their hydrolysis. ${ }^{6}$ For the five-membered methyl ethylene phosphate Westheimer reported ${ }^{6} 7-9 \mathrm{kcal} \cdot \mathrm{mol}^{-1}$ on the basis of comparison of the heats of hydrolysis of trimethyl phosphate $\left(\sim 20 \mathrm{kcal} \cdot \mathrm{mol}^{-1}\right)$ and methyl ethylene phosphate $\left(29.5 \mathrm{kcal} \cdot \mathrm{mol}^{-1}\right)$. Therefore, assuming that the change of entropy due to polymerization is lower than 10 e.u., it is not surprising that in the polymerization of methyl ethylene phosphate, at or close to $25^{\circ}$, the polymer yield was practically quantitative.

In contrast to the five-membered esters the sixmembered ones are much less strained and in their polymerization the polymer-monomer equilibrium is clearly seen. ${ }^{7}$ The ring strain, according to the heats of hydrolysis, is close to $1.0 \mathrm{kcal} \cdot \mathrm{mol}^{-1}$.

In the anionic and cationic processes polymerization comes to equilibrium; this has been detected by dilatometric measurements.

Taking advantage of the fact, that polymerization of cyclic esters of phosphoric acid can be induced by anionic as well as by cationic initiators, the thermodynamic parameters have been compared for those two different mechanisms.

In Table 1 these parameters are given for the polymerization of 2-methyl-2-oxo-1,3,2-dioxaphosphorinanę.

In spite of the large scatter of the experimental data in the anionic polymerization, results for both anionic and cationic procésses are in reasonably good agreement.

Heat of polymerization, reflecting mostly the ring

Table 1. Thermodynamic parameters in the anionic and cationic polymerization of 2-methyl-2-oxo-1,3,2-dioxaphosphorinane ${ }^{7,8}$

\begin{tabular}{ccc}
\hline $\begin{array}{c}\text { Thermodynamic } \\
\text { function }\end{array}$ & $\begin{array}{c}\text { Anionic } \\
\text { polymerization }\end{array}$ & $\begin{array}{c}\text { Cationic } \\
\text { polymerization }\end{array}$ \\
\hline $\begin{array}{c}\Delta H_{1 s} \\
\left(\mathrm{kcal} \cdot \mathrm{mol}^{-1}\right) \\
\dagger \Delta S_{1 s}^{\circ}\end{array}$ & $-0.7 \pm 0.5$ & $-1.1 \pm 0.1$ \\
$\begin{array}{c}\left(\mathrm{cal} \cdot \mathrm{mol}^{-1} \cdot{ }^{\circ} \mathrm{K}^{-1}\right) \\
(\mathrm{e.u.})\end{array}$ & $-2.8 \pm 1.5$ & $-5.4 \pm 0.1$ \\
$\begin{array}{c}\Delta G_{1 s} \\
\left(\mathrm{bulk}, 25^{\circ}\right) \\
\left(\mathrm{kcal} \cdot \mathrm{mol}^{-1}\right) \\
\Delta G_{1 s}^{\circ}\end{array}$ & $\ddagger$ & $-0.8 \pm 0.1$ \\
$\left(\mathrm{kcal} \cdot \mathrm{mol}^{-1}\right)$ & $\ddagger$ & $+0.5 \pm 0.1$ \\
\hline
\end{tabular}

$T_{c}=390^{\circ}$ (bulk).

$\dagger$ A superscript ${ }^{\circ}$ denotes standard conditions: $298^{\circ} \mathrm{K}$ and $[M]_{0}=$ $1.0 \mathrm{~mol} \cdot 1^{-1}$.

$\ddagger$ Not given, because of the large scatter in $\Delta H_{1}$ and $\Delta S_{1 s}^{\circ}$ determined for the anionic polymerization. strain, is low (approx $1.0 \mathrm{kcal} \cdot \mathrm{mol}^{-1}$ ) and close to the value determined in hydrolysis.

Although $\Delta G_{1 s}^{\circ}$, calculated for six-membered cycloalkanes are strongly positive, a number of six-membered ring compounds are known to polymerize quite easily.' Negative values of $\Delta G_{1 \text { s }}^{\circ}$ were reported for puckered six-membered cyclic siloxanes and cyclic esters (e.g. $\delta$-valerolactone, ethylene oxalate, etc.). ${ }^{10}$

The bond angles in monomer and those in the open-chain esters are almost identical. Therefore, the observed negative $\Delta H_{1 s}$ is probably caused by a conformational and transannular strain (nonbonded intramolecular interactions between the axial $\mathrm{H}$ atoms).

In the polymerization of cyclic esters of phosphoric acid there is a possibility of the sketal $d_{\pi}-p_{\pi}$ interactions, but there is no clear cut evidence, that any homologue is preferentially stabilized by these effects.

Our value of $\Delta S_{1 s}^{\circ}=-5.4$ e.u. can be explained on the basis of the usually considered individual contributions of the component entropy changes. ${ }^{10}$ This value is to be compared with $\Delta S_{1 s}^{\circ}$, calculated for a hypothetical polymerization of cyclohexane ( -2.5 e.u.), methylcyclohexane (-7.6 e.u.), or a six-membered lactam $(-6.6$ e.u. $)$. $^{10}$

Conversion of a six-membered cyclic phosphate into a polymer results in a large increase in the rotational and vibrational entropy because of the enhanced flexibility of the open chain monomer unit. As a consequence the entropy change, mostly due to aggregation processes, is less negative in the polymerization of the medium and large ring heterocycles than in the polymerization of the unsaturated monomers.

Comparison of $\Delta G_{1 s}^{\circ}$ and $\Delta G_{1 s}$ from Table 1 indicates that polymerization in solution, under standard conditions, is not energetically feasible. As it will be shown in the next paragraphs, polymerization at room temperature becomes feasible in bulk $\left(\Delta G_{1 c}<0\right)$, yet kinetically inhibited, because the activation energy of propagation is high enough to make the rate of polymerization impractically low. There is a number of known cases in the ring-chain equilibria for which similar phenomena were observed. ${ }^{11}$

Determination of the thermodynamic parameters in the polymerization of 2-alkyl-2-oxo-1,3,2-dioxaphosphorinanes with larger exocyclic alkyl substituents (alkyl $=$ ethyl, $n$-propyl, trimethylsilyl) revealed, that the increase of bulkiness results in a decrease in the enthalpy of polymerization and in a simultaneous increase in the entropy change.

Thermodynamic data obtained in the cationic polymerization and discussed above is given in Table 2 .

Table 2. Thermodynamic parameters in the cationic polymerization of 2-alkyl-2-oxo-1,3,2-dioxaphosphorinanes ${ }^{12}$

\begin{tabular}{cccc}
\hline & \multicolumn{3}{c}{ Alkyl exocyclic group } \\
\cline { 2 - 4 } $\begin{array}{c}\text { Thermodynamic } \\
\text { function }\end{array}$ & Ethyl & $n$-Propyl & Trimethylsilyl \\
\hline $\begin{array}{c}\Delta H_{1 s} \\
\left(\mathrm{kcal} \cdot \mathrm{mol}^{-1}\right) \\
\Delta S_{1 s}^{\circ}\end{array}$ & $1.4 \pm 0.6$ & $2.7 \pm 0.4$ & $3.9 \pm 1.3$ \\
$\begin{array}{c}(\mathrm{e} . \mathrm{u} .) \\
\Delta G_{\text {觔 }}^{\circ}\end{array}$ & $2.6 \pm 1.4$ & $5.7 \pm 1.1$ & $8.7 \pm 3.3$ \\
$\left(\mathrm{kcal} \cdot \mathrm{mol}^{-1}\right)$ & $0.6 \pm 0.1$ & $1.0 \pm 0.1$ & $1.3 \pm 0.3$ \\
$\begin{array}{c}\Delta G_{1 s} \dagger \\
\left(\mathrm{kcal} \cdot \mathrm{mol}^{-1}\right)\end{array}$ & $-0.7 \pm 0.1$ & $-0.15 \pm 0.1$ & $\sim 0$ \\
$T_{f}(\mathrm{bulk})^{\circ} \mathrm{C}:$ & -60 & +9 & +53 \\
\hline
\end{tabular}

†Bulk, $25^{\circ}$. 
Plot of $\Delta H_{1 s}$ against $\Delta S_{1 s}^{\circ}$ for monomers listed in Tables 1 and 2 is a straight line, showing the usual compensation phenomena. Starting from the ethyl monomer, polymerization becomes driven by a positive entropy change. Apparently, the rotational freedom of the exocyclic group becomes more and more restricted in monomers when the bulkiness of these groups increases. Indeed, analysis of the Stuart molecular model of 2-trimethylsilyl-2-oxo1,3,2-dioxaphosphorinane shows that the rotation of the silyl group is completely frozen by the $\mathrm{H}$ atoms in axial positions, bound to the carbon atoms in $\beta$-position from phosphorus:

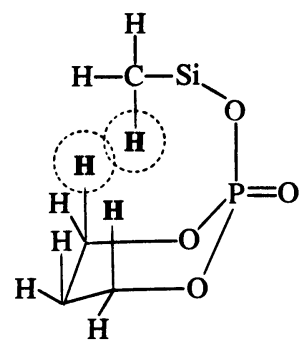

Interacting axial hydrogen atoms from the ring are shown in the bold-faced type.

Increase in the enthalpy change and the passage from the slightly exothermic polymerization of the methyl monomer to the slightly endothermic polymerization for higher alkyl substituents means that the enthalpy of polymer becomes higher than that of monomer. This has its origin in agreement with known spectra of esters of phosphoric acid. $^{15}$

Methyl ethylene phosphate gives in ${ }^{31} \mathrm{P}\left\{{ }^{1} \mathrm{H}\right\}-\mathrm{NMR}$ spectrum a singlet at $-17.89 \delta$ (from $\mathrm{H}_{3} \mathrm{PO}_{3}$ ). This absorption was used to check the presence of monomer in polymer or in a polymerization mixture. ${ }^{31} \mathrm{P}\left\{{ }^{1} \mathrm{H}\right\}-\mathrm{NMR}$ spectrum of the polymerization mixture, recorded after completion of the polymerization of methyl ethylene phosphate, consists only of one singlet at 0.08 . This fact indicates not only that the polymer chain consists exclusively of the units shown above, but in addition it indicates that no side products are formed.

Polymerization of several 2-alkyl-2-oxo-1,3,2dioxaphospholanes has been studied (alkyl = ethyl, $n$ propyl, $i$-propyl, 1,1,1,-trifluoroethyl, and 1,1,1trichloroethyl) and in all the cases both ${ }^{1} \mathrm{H}$ and ${ }^{31} \mathrm{P}$ spectra indicated linear structure of polymers. Molecular weights of polymers are high $\left(\bar{M}_{n}=10^{4}-10^{5}\right)$ and the end groups could not be detected by NMR.

Anionic and cationic polymerization of the sixmembered dioxaphosphorinanes leads to oligomeric products $\left(\bar{M}_{n}<5.10^{3}\right)$ and the microstructure of the chains could be studied in greater detail by NMR, including the end groups.

${ }^{1} \mathrm{H}$ and ${ }^{31} \mathrm{P}-\mathrm{NMR}$ spectra are identical for the anionic and cationic polymers. These spectra, as will be shown, are fully consistent with a linear structure of a macromolecule, having, in the case of the 2-methyl-2-oxo1,3,2-dioxaphosphorinane, dimethyland cyclic end-groups.

Four singlets, three of which are assigned as below, are observed in ${ }^{31} \mathrm{P}\left\{{ }^{1} \mathrm{H}\right\}-\mathrm{NMR}$ spectrum:<smiles>COP(=O)(OC)OCCCCOP(=O)(OC)OCCCOP1(=O)OCCCO1</smiles>

in the increase of a number of degrees of freedom, higher apparently in polymer than in monomer and energetically outweighing the energy difference due to the ring strain. Thus, the polymerization of monomers with bulky substituents resembles polymerization of sulfur, selenium, and some cyclosiloxanes, for which simultaneously $\Delta H>$ 0 and $\Delta S>0 .{ }^{13}$

\section{STRUCTURE OF POLYMERS}

${ }^{1} \mathrm{H},{ }^{31} \mathrm{P}$ and ${ }^{13} \mathrm{C}-\mathrm{NMR}$ spectra of polyesters of phosphoric acid have been studied in this laboratory. The presence of phosphorus atoms in the chain, coupled to both $\mathrm{H}$ and $\mathrm{C}$ atoms, provides an additional source of information.

The ${ }^{1} \mathrm{H}\left\{{ }^{31} \mathrm{P}\right\}-\mathrm{NMR}$ (decoupled from phosphorus) spectra of poly(methyl ethylene phosphate) of high molecular weight $\left(\bar{M}_{n}>10^{4}\right)$ :<smiles>CCCOP(=O)(O)OC</smiles>

and measured in $\mathrm{D}_{2} \mathrm{O}$ solvent consists exclusively of two singlets characteristic for protons of the methylene groups and exocyclic methyl groups. ${ }^{14}$ The ${ }^{31} \mathrm{P}\left\{{ }^{1} \mathrm{H}\right\}-\mathrm{NMR}$ spectra shows one singlet at $0.0 \delta$ (from $\mathrm{H}_{3} \mathrm{PO}_{3}$ internal),
The fourth singlet is observed, at $+1.1 \delta$.

According to the previously given detailed analysis of the NMR spectra, ${ }^{7,8}$ the central line at $0.0 \delta$ belongs to the $P$ atoms in the backbone (shown in the brackets above), the line at $-1.0 \delta$ probably to the end group, bearing two methyl groups, and that at +1.1 either to the $P$ atom next to the cyclic end groups and/or to the $P$ atom in the linear end group in a dimer. The line at $7.0 \delta$ can only be due to the cyclic end group ( $P$ in methyl monomer absorbs at $6.0 \mathrm{\delta}$; no absorption at this position was observed in polymer). The absence of monomer was also confirmed by ${ }^{13} \mathrm{C}$ spectra. Thus, in ${ }^{13} \mathrm{C}\left\{{ }^{1} \mathrm{H}\right\}-F P T-N M R$ spectra carbon atoms in the exocyclic methyl groups of monomer give a doublet (because of the splitting by P) at $53.5 \delta$ (from TMS), which is not observed in polymer.

In principle, the multiplicity of $\mathbf{P}$ absorptions, not decoupled from ${ }^{1} \mathrm{H}$, could be used to check these assignments, however the $\mathrm{cw}^{31} \mathrm{P}$ spectra are not sufficiently well resolved for this treatment.

The ${ }^{1} \mathrm{H}\left\{{ }^{31} \mathrm{P}\right\}-\mathrm{NMR}$ spectra also confirm the structure shown by the polymer formula 5 . The source of the $\mathrm{H}$-atom nonequivalence in monomer, due to the interactions of $\mathrm{H}$ atoms at the axial and equatorial positions, is now eliminated and $\mathrm{H}_{4}$ and $\mathrm{H}_{6}$ give, in a polymer, a triplet at $4.23 \delta$ with ${ }^{3} \mathrm{~J}_{\mathrm{HH}}=6 \mathrm{~Hz}$. Superimposed (at $60 \mathrm{MHz}$ ) on this triplet are three lines at $4.38,4.45$, and $4.50 \delta$, close to the positions belonging to $\mathrm{H}_{4}$ and $\mathrm{H}_{6}$ (axial and equatorial) of monomer (the fourth line, observed in monomer at $4.35 \delta$ is covered by 
a polymer triplet). Since, according to the analysis of ${ }^{13} \mathrm{C}$ and ${ }^{31} \mathrm{P}-\mathrm{NMR}$ spectra show there is no monomer left in the polymer. These lines were interpreted, in accordance with ${ }^{31} \mathrm{P}\{\mathrm{H}\}-\mathrm{NMR}$ spectra, as coming from cyclic end-groups.

The concentration of the cyclic end-groups, determined from ${ }^{1} \mathrm{H}\left\{{ }^{31} \mathrm{P}\right\}$ and ${ }^{31} \mathrm{P}\left\{{ }^{1} \mathrm{H}\right\}-\mathrm{NMR}$ spectra are usually in agreement, within $20-30 \%$, with their concentrations determined from measurements of $\overline{\mathrm{DP}}_{n}$ (vpo), if an assumption is made that there is one cyclic end-group in every macromolecule.

\section{KINETICS AND MECHANISM OF POLYMERIZATION}

\section{Anionic polymerization ${ }^{8}$}

Kinetic plots of the anionic polymerization, initiated in bulk or in solution of diglyme or DMSO by $\mathrm{C}_{2} \mathrm{H}_{5} \mathrm{ONa}$, in the temperature region $60-120^{\circ}$, revealed the following basic features:

(1) Polymerization is internally and externally of the first order with respect to monomer, from the very beginning of the reaction until the polymer-monomer equilibrium is attained,

(2) At the lower initiator concentrations (up to $10^{-2} \mathrm{~mol} \cdot \mathrm{l}^{-1}$ ) polymerization is first order with respect to initiator and above this concentration the order drops to $1 / 3$.

(3) Substitution of a part of monomer by diglyme lowers the rate of polymerization by a factor close to 3.0.

On the basis of these findings it is assumed that the growing species are formed quantitatively at the sufficiently low concentration of initiator. Thus, the rate constants for propagation could be determined directly from the kinetic plots, described by the following expression:

$$
\ln \left\{\left([M]_{0}-[M]_{\infty}\right) /\left([M]_{t}-[M]_{\infty}\right\}=k_{p}^{\mp} \cdot\left[\mathrm{P}^{\mp}\right] \cdot t\right.
$$

where

$$
\left[\mathrm{P}^{\mp}\right]=[I]_{0}
$$

We are using notation $\mp$ as a superscript, because the predominant presence of the free ions is not probable (cf. also (2) at the high temperatures at which the polymerization was studied, and at initiator concentrations as high as $10^{-3}-10^{2} \mathrm{~mol} \cdot \mathrm{l}^{-1}$.

Monomer itself is a highly polar compound $(\epsilon=31.4)$ and it was assumed, that at the large excess of monomer over ions the latter become monomer-separated. Only at still higher concentration of the growing species the tendency to trimerization into the less active or completely inactive species is apparent (cf. (2)). ${ }^{8}$

Thus, the determined, according to eqn (1), rate constant of propagation was interpreted as the rate constant of the chain growth on the monomer-separated ion pairs.

The anionic chain growth of the six-membered dioxaphosphorinanes is slow and the rate constants of propagation have low values even at higher temperatures. Thus, at $125^{\circ}, k_{p}^{\mp}$ equals only $8.3 \cdot 10^{-4} \cdot 1 \cdot \mathrm{mol}^{-1} \cdot \mathrm{sec}^{-1}$.

Determination of $k_{p}^{\mp}$ at various temperatures allowed the activation parameters to be calculated:

$$
\begin{aligned}
\Delta H_{p}{ }^{\neq} & =26.3 \mathrm{kcal} \cdot \mathrm{mol}^{-1} \\
\Delta S_{p}{ }^{\neq} & =-6.1 \mathrm{cal} \cdot \mathrm{mol}^{-1} \cdot{ }^{\circ} \mathrm{K}^{-1}
\end{aligned}
$$

Thus propagation is mainly hampered by a high enthalpy of activation. Entropy of activation is, on the other hand, unusually low as for a bimolecular reaction. ${ }^{16}$ The further significance of these values will be discussed below in connection with a proposed mechanism of propagation.

From a mechanistic standpoint the anionic propagation of cyclic phosphates has much in common with a basic hydrolysis of these compounds. The modern theory of the base-catalysed hydrolysis of phosphates describes this process as a nucleophilic attack on phosphorus. ${ }^{1,17}$ The corresponding transition state is described as a trigonal bipyramid, in which a phosphorus atom is bound to five ligands: three in equatorial and two in apical positions. The apical P-O bonds are longer and weaker than the equatorial ones. It is generally accepted, that an attack of the nucleophilic reagent on the phosphorus atom comes from the apical direction. Therefore, to fulfill the requirements on the principle of microreversibility the leaving group should also be located in the apical position.

Our proposed mechanisms of the elementary reactions in the anionic polymerization are based on the described above theory of the base-catalysed hydrolysis.

\section{Anionic initiation and propagation}

Initiation by an alcoholate anion (given below for 2methyl-2-oxo-1,3,2-dioxaphosphorinane) can, therefore, be presented as a nucleophilic attack on phosphorus atom, leading to the trigonal bipyramid:

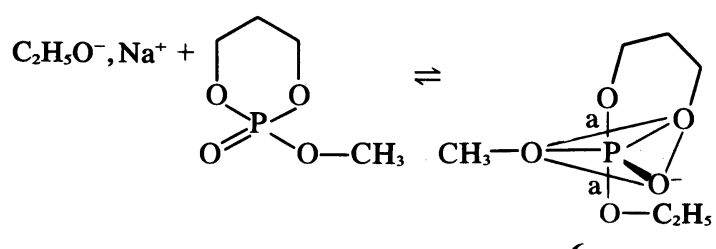

6

In structure 6 the negative charge is distributed among the oxygen atoms and, in principle, the $\mathrm{P}-\mathrm{O}$ bond could be broken at any ligand, but the apical bonds are preferred because of their enhanced weakness. The six-membered ring is shown in 6 to occupy the axial-equatorial position, because this is the preferred structure the ring compounds have according to the X-ray studies. ${ }^{17}$ Therefore, in 6 the apical (marked $a$ in 6) bond is broken, and the new alcoholate anion is produced; this one is already a growing centre of propagation:

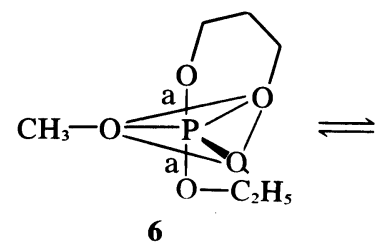<smiles>CCOP(=O)(OCCC[O-])OOC</smiles>
7

Thus formed growing anionic centre participates in the chain growth by attacking the phosphorus atom in the next monomer molecule and reproducing a structure similar to 6 .

Thus, in short, the growing active species have the structure of the alcoholate anion and the chain propagation consists of an attack by these species on the elec- 
<smiles>CCOP(=O)(OC)OCCC[O-]</smiles>

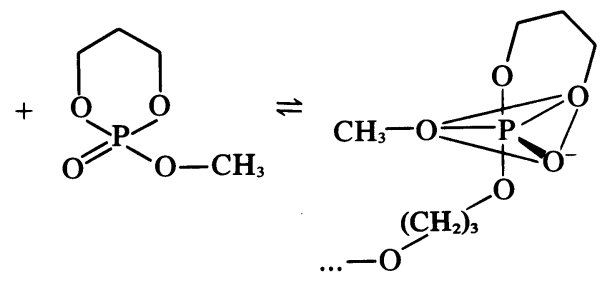

6a

trophilic phosphorus atom in the monomer molecule. This attack is directed along the apical position and leads to the formation of the transition state (or a high energy intermediate product), having the structure of a trigonal bipyramid.

Chain growth is reversible and ring opening $\rightleftharpoons$ ring closure equilibrium should use the same reaction pathway. Both involve an attack along the apical positioin, as shown according to eqns (4) and (5):

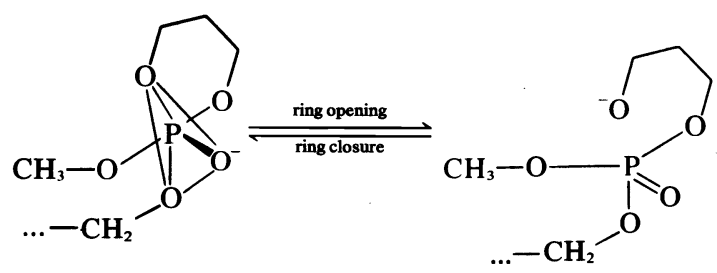

\section{ANIONIC CHAIN TRANSFER}

Polymers prepared by anionic polymerization of 2alkyl-2-oxo-1,3,2-dioxaphorinanes have rather low molecular weights and every macromolecule has one cyclic end-group, as shown in 5.

This could easily be explained if we assume that in the transition (intermediate) state $6 \mathrm{~A}$ the ring remains intact and that the other axial $\mathrm{P}-\mathrm{O}$ bond breaks, giving $\mathrm{a}_{3} \mathrm{O}^{-}$anion and a neutral macromolecule with a ring at its end. This would, however, require the exocyclic group toleave froma much more stable equatorial position. A similar problem has been faced in the hydrolysis of the cyclic phosphates and it was proposed, that structures similar to $6 \mathrm{~A}$ can change the position of substituents by a process called pseudorotation. Application of the theory of pseudorotation to the explanation of the anionic chain transfer calls for the exchange of the equatorial position of the exocyclic group to the apical one. This is possible if structure 6A is allowed to pseudorotate along the $\mathrm{P}_{-} \mathrm{O}^{-}$bond taken as a pivot. This pseudorotation is formally equivalent to changing the positions of the methoxy and polymeric chain substituents:

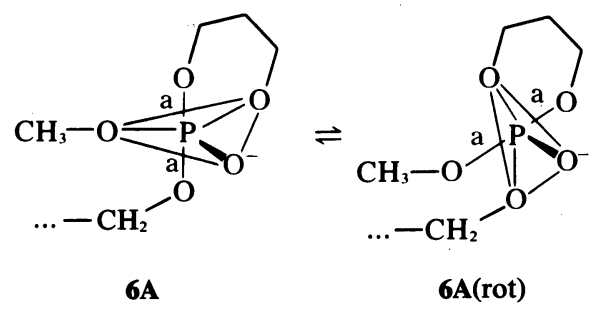

The exocyclic methoxy group located (6A(rot)) at the apical position, leaves the growing chain as a methoxy anion, which reinitiates a new chain:<smiles>COP(=O)(OC)OCCCC[C@H](C)OP1(=O)OCCCO1</smiles>

Thus, in this way the chain transfer (7) provides a cyclic end-group and coupled to reinitiation (8) provides a second end-group, as shown in polymer structure 5 .

\section{ACTIVATION PARAMETERS OF PROPAGATION}

Chain propagation involves a nucleophilic attack of the polymeric alcoholate anion on the $P$ atom in the monomer molecule. According to our description of the process the polymeric ion-pair is monomer separated. This structure can be shown in the following way:

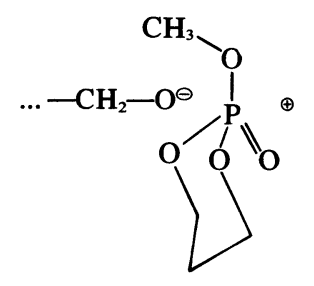

where $\oplus$ denotes a counterion (cation)

The enthalpy of activation of the basic hydrolysis, measured for the $\mathrm{OH}^{-}$anion, usually does not surpass $15 \mathrm{kcal} \cdot \mathrm{mol}^{-1,1,16}$ and is much lower than the enthalpy of activation of propagation that we have measured $\left(26.3 \mathrm{kcal} \cdot \mathrm{mol}^{-1}\right){ }^{8}{ }^{8}$ However, the small $\mathrm{OH}^{-}$anion does not provide an additional strain in the transition state in contrast to the large approaching segment of a macromolecule. Unfortunately, data relating the volume of the attacking nucleophile and that activation energy are not available for cyclic phosphates; it can however, be assumed, that an attack by a polymeric anion requires some additional energy needed for the distortion of the regular trigonal bipyramid. On the other hand, if the chain growth involves a monomer molecule bound in the ion-separated structure 7, then not much of the translational entropy is lost in the chain growth. This may result in an activation entropy as high as -6.1 e.u.

\section{CATIONIC POLYMERIZATION ${ }^{7}$}

Cationic polymerization in bulk of e.g. 2-methyl-2-oxo1,3,2-dioxaphosphorinane, ${ }^{7}$ induced with an initiator bearing stable anion (like $\mathrm{AsF}_{6}^{-}, \mathrm{PF}_{6}^{-}$, or $\mathrm{CF}_{3} \mathrm{SO}_{3}{ }^{-}$) proceeds quite fast above $100^{\circ}$. Thus, polymerization will be complete in a few hours, if the starting concentration of initiator is equal to $10^{-2}-10^{-3} \mathrm{~mol} \cdot 1^{-1}$. 
The main features of the cationic polymerization can be summarized in the following points:

(1) At the sufficiently high concentration of initiator polymerization proceeds to its monomer-polymer equilibrium (cf. paragraph on the thermodynamics of polymerization),

(2) At lower concentration of initiator polymerization stops before the equilibrium is reached,

(3) Polymerization (studied in ethylene chloride solution) is externally first order with respect to monomer.

Initiation of the cationic polymerization was studied by ${ }^{1} \mathrm{H}$ and ${ }^{31} \mathrm{P}-\mathrm{NMR}$ and the structure of the growing species was determined. These species were found to be tetraalkoxyphosphonium ions:<smiles>[R]OP1(OC)(OC)OCCCO1</smiles>

The tetraalkoxyphosphonium ions 8, formed during initiation, were further observed during polymerization by ${ }^{31} \mathrm{P}\left\{{ }^{1} \mathrm{H}\right\} \mathrm{NMR}$ at $0.25 \delta$. The $\left.{ }^{1} \mathrm{H}^{\beta 1} \mathrm{P}\right\}-\mathrm{NMR}$ spectra of 8 , obtained with 1,3-dioxolan-2-ylium $\mathrm{SbF}_{6}^{-} \quad(\mathrm{R}-=$ OHCOCH${ }_{2} \mathrm{CH}_{2}$ in 8) cation in $\mathrm{CD}_{3} \mathrm{NO}_{2}$ and $\mathrm{C}_{2} \mathrm{H}_{4} \mathrm{Cl}_{2}$ solutions, were in agreement with the existing knowledge of the structure of the tetraalkoxyphosphonium ions. ${ }^{18}$ These ions have a tetrahedral structure and the observed equivalency of $\mathrm{H}$ atoms (in contrast to monomer) suggests a conformationally mobile substance. Indeed, the replacement of the $\mathrm{O}=\mathrm{P}$ bond by a $\mathrm{R}-\mathrm{O}-\mathrm{P}$ bond is a source of the absence of any preferred conformation.

\section{CATIONIC CHAIN GROWTH}

If we consider initiation through a cationation at the 2-oxo group, then, the first step of the chain growth can be formulated in the following way:<smiles>[R]OP1(OC)(OC)OCCCO1</smiles><smiles>[R]O[PH](OC)(OC)O[C@H](C)OP1(OC)(OC)OCCCO1</smiles><smiles>[R]OP(=O)(OC)OCCCCO[PH]1(OC)OCCCO1</smiles>

Structure 9, given in the brackets, is only a schematical representation and does not reflect our idea about the transition state, shown below.

Although the attack on the $\mathrm{P}^{+}$cation in 8 and the formation of a pyrophosphoric structure has also been<smiles></smiles>

10

considered as kinetically preferred, 10 cannot be a thermodynamic product, since there is no indication from the NMR studies of the pyrophosphoric chain. The pyrophosphoric structure of the backbone was, however, claimed by Vogt for polymers prepared by polymerization of 2-chloro-2-oxo-1,3,2-dioxaphospholanes. ${ }^{19}$ In this case polymers have the isomerized structure $f(0) \mathrm{P}\left(\mathrm{OCH}_{3}\right)$ $\left(\mathrm{OCH}_{2} \mathrm{CH}_{2} \mathrm{Cl}\right)-\mathrm{O}$ fue to the high reactivity of the chloride exocyclic group.

In the present paragraph, as well as in the former one describing the anionic polymerization, we assume, following, previously expressed view, that the cationic polymerization at/or close to $100^{\circ}$, and at the concentration of the growing species in the region $10^{-3}-10^{-2} \mathrm{~mol} \cdot \mathrm{l}^{-1}$, proceeds mainly on the ion-pairs. Thus, the growing species are the tetraalkoxyphosphonium ions, bound to the corresponding anion.

\section{CHAIN TRANSFER AND CHAIN TERMINATION}

Polymers prepared by cationic polymerization of 2alkyl-2-oxo-1,3,2-dioxaphosphorinanes are of medium molecular weight $\left(\bar{M}_{n}<3000\right)$. Thus, an efficient chain transfer process operates, since otherwise, for a complete consumption of an initiator taken at a concentration of e.g. $10^{-3} \mathrm{~mol} \cdot 1^{-1}$, degree of polymerization for a bulk polymerization $\left([M]_{0} \cong 8.0 \mathrm{~mol} \cdot 1^{-1}\right)$ should approach $10^{4}$. This is more than $10^{2}$ times higher than the actually observed value. On the other hand, the low degrees of polymerization are not merely due to the presence of impurities, because the polymer structure shows definite end-groups (structure 5).

Remembering, that the growing species have the structure of the tetraalkoxyphosphonium ions, the competition between chain growth and chain transfer can be represented in the following way:<smiles>CCOP12(OC)CO[PH](OC)(OCCO1)O2</smiles>

(where $\mathrm{O}=\mathrm{P} \frac{L}{\perp}$ is a part of an incoming molecule of monomer)

In tetraalkoxyphosphonium ions a partial positive charge is localised on carbon atoms $\mathrm{C}_{4}$ and $\mathrm{C}_{6}$, being a part of the ring, and on the exocyclic $\mathrm{C}_{8}$ atom. Therefore, when an $\mathrm{O}_{3}-\mathrm{C}_{4}$ bond (or equivalent $\mathrm{O}_{1}-\mathrm{C}_{6}$ bond) is broken chain propagation takes place, if however, the $\mathrm{O}_{\tau}-\mathrm{C}_{8}$ bond is etc. broken in 11, then chain transfer proceeds. 
Because of the low ring strain in the six-membered cyclic phosphates (approx. $1.0 \mathrm{kcal} \cdot \mathrm{mol}^{-1}$ ), both reactions proceed with comparable rate constants.

Chain transfer in 11 leaves an oligomer with a cyclic end-group and leads to reinitiation by forming a new tetraalkoxyphosphonium ion: and termination on polymer. Solution of this scheme was given by the present writer and Kubisa ${ }^{20}$ for a polymerization without depropagation, and the derivation given there applies also to the present system. It needs in fact only a slight modification in order to take account of a depropagation reaction.
11

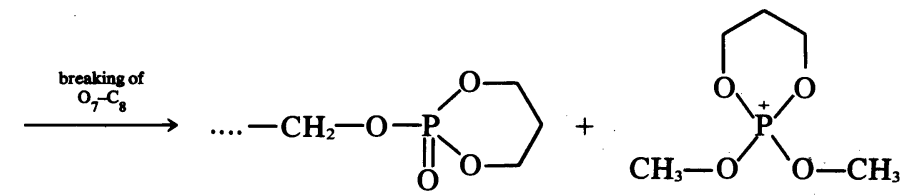

Chain transfer has no kinetic effect, because the reinitiation is fast.

In the polymerization of the higher 2-alkyl-2-oxo-1,3,2dioxaphosphorinanes the combined GLC-MS method revealed that the following gaseous products are formed: (exocyclic groups in corresponding monomers are given first) ethyl: ethylene; $\boldsymbol{n}$-propyl, $\boldsymbol{i}$-propyl: propylene; cyclohexyl: cyclohexene. This is a further confirmation of the proposed mechanism of chain transfer, schematically shown in eqn (12). Apparently, in monomers with larger alkyl substituents, formation of an olefin and proton transfer to the incoming monomer molecule proceed in a concerted mechanism.

The previously described kinetic features show that in the cationic polymerization, in contrast to the anionic process, chain termination takes place.

An attempt was made to find a mechanism of chain termination which; after solution of a set of the pertinent kinetic equations, would fit the experimental data. From several potential chain termination mechanisms, a chain termination involving reaction of the growing centre with a polymer segment was selected.?

By an analogy with the chain growth, chain termination can be visualized by reaction (13):
The final kinetic equation reads as follows:

$$
\begin{aligned}
& -\frac{\mathrm{d} \ln \left([M]-[M]_{e}\right)}{\mathrm{d} t}=k_{p}^{ \pm}[I]_{0}-k_{t}^{ \pm} \\
& \times\left\{\left([M]_{0}-[M]_{e}\right) \ln \frac{[M]_{0}-[M]_{e}}{[M]-[M]_{e}}-\left([M]_{0}-[M]\right)\right\}
\end{aligned}
$$

In deriving eqn (14) it was assumed that the starting concentration of initiator $\left([I]_{0}\right)$ is equal to the sum of concentrations of the strained cyclic ions (growing) (8), and nonstrained (like12), which are unable to grow.

By using eqn (14) $k_{p}^{ \pm}$and $k_{t}^{ \pm}$could separately be determined, and, remembering that $1 /[M]_{e}=k_{p}^{ \pm} / k_{d}^{ \pm}, k_{d}^{ \pm}$ could also be calculated.

The dependence of these constants on temperature gave the corresponding thermodynamical activation parameters. These are given in Table 3.

The only work, in which activation parameters have been determined for both propagation and degradative chain transfer to polymer (termination) is a cationic polymerization of cyclic sulphides and phosphates (Table 3). The activation enthalpy of polymerization is much higher than that of termination, and the entropy of activation of the<smiles>CCOP(=O)(OCC)OCCCCOP(=O)(OC)OCCCCO[P+](OC)(OCC)OCC</smiles>

Reaction (13) extends the already known chemistry of termination of cyclic ethers ${ }^{20}$ and cyclic sulphides ${ }^{21}$ to cyclic phosphates. Indeed, it has been pointed out, that the degradative chain transfer to polymer, (equivalent to termination) is a general feature of the cationic polymerization of heterocyclic monomers. ${ }^{22,23}$ In the polymerization of cyclic phosphates this is a reaction similar to that of the chain growth, but leading to the nonstrained tetraalkoxyphosphonium ions, which are unable to reinitiate chain growth.

\section{KINETIC SCHEME OF CATIONIC POLYMERIZATION} AND RATE CONSTANTS OF ELEMENTARY REACTIONS

If complete scheme of polymerization, provided that initiation is a fast reaction in comparison with a chain growth, consists of propagation, depropagation termination reaction is much more negative than that of propagation.

The observed difference in enthalpy of activation between the propagation and termination reactions can be attributed to the difference in basicities between monomer

Table 3. Activation parameters of the elementary reactions in the cationic polymerization of 2-methyl-2-oxo-1,3,2dioxaphosphorinane

\begin{tabular}{lcc}
\hline Elementary reaction & $\begin{array}{c}\Delta H^{*} \\
\left(\mathrm{kcal} \cdot \mathrm{mol}^{-1}\right)\end{array}$ & $\begin{array}{c}\Delta S^{*} \\
\left(\mathrm{cal} \cdot \mathrm{mol}^{-1} \cdot{ }^{\circ} \mathrm{K}^{-1}\right)\end{array}$ \\
\hline Propagation & 19.5 & -15.6 \\
Depropagation & 20.6 & -10.2 \\
Termination & 11.6 & -48.2 \\
\hline
\end{tabular}


$\left(p K_{a}=3.1\right)$ and a linear polymer segment $\left(p K_{a}=3.8\right)$ (both measured by us on the basis of the optical density shift in $\mathrm{CH}_{3} \mathrm{OD}$ ). The large difference in entropies of activation may be due to the freezing of a much larger number of atoms when a polymer segment is immobilized in the activated complex.

Polymerization of higher alkyl-2-oxo-1,3,2dioxaphosphorinanes revealed, that for monomer with a sufficiently large exocyclic group (e..g trimethylsilyl) chain termination becomes eliminated completely. Apparently, the very large negative change of entropy, which would accompany termination, is responsible for this phenomenon. However, chain transfer is even more pronounced than with a methyl derivative, and, eventually, polymerization degrees decrease with an increase in the size of the exocyclic group.

POLYMERIZATION OF 2-HYDRO-2-0X0-1,3,2DIOXAPHOSPHORINANE ${ }^{14}$ AND PREPARATION OF POLY(P-HYDROXY ALKYLENE PHOSPHATES)

Although other routes are also being studied in our laboratory, in one of the successful preparations of the high molecular weight polymers having the structure of 1,3-propylene phosphates, 2-hydro-2-oxo-1,3,2dioxaphosphorinane was used as a monomer:<smiles>O=[PH]1OCCCO1</smiles>

13

$$
\left.\longrightarrow+\mathrm{CH}_{2}-\mathrm{CH}_{2}-\mathrm{CH}_{2}-\mathrm{O}-\prod_{\mathrm{P}}^{\mathrm{P}}-\mathrm{O}\right)_{\mathrm{n}}
$$

poly(P-hydro 1,3-propylene phosphonate)

14

According to the ${ }^{1} \mathrm{H}$ and ${ }^{31} \mathrm{P}-\mathrm{NMR}$ spectra, conversion of monomer (13) into polymer (14) is practically quantitative at room temperature. Apparently, formation of the high-molecular weight polymers is connected with the absence of the exocyclic ester group, which is responsible in 2-alkyl-2-oxo-1,3,2-dioxaphosphorinanes for an extensive chain transfer, as described in previous paragraphs.

In 13 absorption of $\mathrm{H}-\mathrm{P}$ is observed as a doublet, centered at $6.90 \delta\left(\mathrm{J}_{\mathrm{PH}}=675 \mathrm{~Hz}\right)$ and in 14 at $6.95 \delta$ $\left(\mathrm{J}_{\mathrm{PH}}=725 \mathrm{~Hz}\right)$.

Oxidation of 14 by $\mathrm{N}_{2} \mathrm{O}_{4}$ in $\mathrm{CH}_{2} \mathrm{Cl}_{2}$ at $0^{\circ}$ according to Denney $^{24}$ led to the corresponding polyacid(poly $(\mathrm{P}$ hydroxy 1,3-propylene phosphate): a highly elastic, transparent solid material

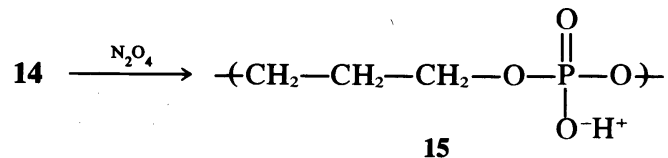

Transformation of $\mathbf{1 4}$ into $\mathbf{1 5}$ leads to the complete disappearance of the $\mathrm{H}$ atom bound to $\mathrm{P}$ atoms, and observed in ${ }^{1} \mathrm{H}-\mathrm{NMR}$ as a characteristic doublet with the large coupling constant given above.

Some chemical transformations, including oxidation, were reported previously for poly $(\mathrm{P}$-hydroxy hex- amethylene phosphonate) prepared by polycondensation. $^{25}$

In order to prepare polyacids similar to 15 , but with a shorter alkylene unit, namely poly(P-hydroxy ethylene phosphate) the corresponding poly(methyl ethylene phosphate) was used as the starting material.

The following sequence of reactions led to the high molecular weight poly(P-hydroxy ethylene phosphate) (18):<smiles>CCOP(=O)(OC)OC</smiles><smiles>CCCCOP(=O)(O[Na])O[N+](C)C</smiles><smiles>CCCCOP([O])(=O)O</smiles>

18

The successive steps and the extent of the reactions were controlled by ${ }^{1} \mathrm{H}\left\{{ }^{31} \mathrm{P}\right\}-\mathrm{NMR}$. A characteristic singlet due to $-\mathrm{CH}_{3}$ in 16 at $3.8 \delta$ disappeared after the dealkylation step (treatment with $\mathrm{N}\left(\mathrm{CH}_{3}\right)_{3}$ in water solution at $25^{\circ}$ ). According to ${ }^{1} \mathrm{H}-\mathrm{NMR}$ the dealkylation exceeds $90 \%$. A singlet at $3.15 \delta$, due in 17 to protons in the methyl groups disappeared completely after passing a water solution of 17 through a column packed with a cation exchanging resin. ${ }^{1} \mathrm{H}\left\{{ }^{31} \mathrm{P}\right\}-\mathrm{NMR}$ spectrum of 18 in $\mathrm{D}_{2} \mathrm{O}$ consists of only one singlet at $4.3 \delta\left(\mathrm{CH}_{2}-\mathrm{CH}_{2}\right)$ and small residue of the methyl groups from 16.

Thus, polymerization of cyclic esters can eventually lead to the poly(P-hydroxy alkylene phosphates), having backbones similar to some naturally occuring polymers like nucleic acids (3), teichoic acid (4) etc. Preparation of the high molecular weight polymers opens new possibilities in studying this new class of synthetic models of biopolymers.

Acknowledgement-This work was supported in part by a grant of the Polish Academy of Sciences (No. 0.3.1.2).

\section{REFERENCES}

'J. R. Cox, Jr and O. B. Ramsay, Chem. Revs. 64, 317 (1964); C. A Bunton, Accounts Chem. Res. 3, 257 (1968).

${ }^{2} \mathrm{~S}$. Patai, The Chemistry of Carboxylic Acids and Esters. Interscience, New York (1969).

${ }^{3} \mathrm{G}$. Kosolapoff, Organophosphorous Compounds. John Wiley, New York (1950).

${ }^{4} \mathrm{~J}$. Baddiley, Accounts Chem. Res. 3, 98 (1970).

${ }^{5}$ E. J. Vandenberg, US Pat. 3520849 (1969), (to Hercules Inc.).

${ }^{6} \mathrm{~J}$. R. Cox, Jr, R. E. Wall and F. H. Westheimer, Chem. Ind. 929 (1959); F. H. Westheimer, Accounts Chem. Res. 1, 70 (1968).

${ }^{7}$ G. Kapienis and S. Penczek, Macromolecules 7, 167 (1974).

${ }^{8}$ G. Kapienis and S. Penczek, J. Polymer Sci. (1976). To be published.

${ }^{9}$ H. Sawada, J. Macromol. Sci., Revs. Macromol. Chem. 5, 151 (1970).

${ }^{10} \mathrm{~F}$. S. Dainton and K. J. Ivin, Quart. Rev. (London) 12, 61 (1958); K. J. Ivin, Angew. Chem. 85, 533 (1973).

${ }^{11}$ H. R. Allcock, J. Macromol. Sci., Revs. Macromol. Chem. 4, 149 (1970).

${ }^{12} \mathrm{G}$. Kapienis and S. Penczek, in preparation. 
${ }^{13} \mathrm{M}$. Szwarc, Carbanions, Living Polymers and Electron Transfer Processes. Chap. 3, Interscience, New York (1968).

${ }^{14} \mathrm{~J}$. Libiszowski, K. Ka\użynski and S. Penczek, Macromolecules. 9, 365 (1976).

${ }^{15}$ V. Mark, C. H. Dungan, M. M. Crutchfield and J. R. Van Wazer, Compilation of ${ }^{31} \mathrm{P}$ NMR data in: Topics in Phosphorus Chemistry. (Edited by M. Grayson and E. J. Griffith) Vol. 5. Interscience, New York (1967).

${ }^{16} \mathrm{~L}$. L. Shaleger and F. A. Long, Entropies of activation and mechanisms of reactions in solution in : Advances in Phys. Org. Chem. (Edited by V. Gold) Vol. 1, p. 1. Academic Press, London (1963).

${ }^{17} \mathrm{G}$. Aksnes and K. Bergesen, Acta Chem. Scand. 20, 2508 (1966).
${ }^{18} \mathrm{~J}$. H. Finkley, D. Z. Denney and D. B. Denney, J. Am. Chem. Soc. 91, 5826 (1969)

${ }^{19} \mathrm{~W}$. Vogt, Makromol. Chem. 163, 89 (1973).

${ }^{20} \mathrm{P}$. Kubisa and S. Penczek, Makromol. Chem. 130, 186 (1969).

${ }^{21}$ E. J. Goethals and W. Drijvers, Makromol. Chem. 136, 73 (1970).

${ }^{22}$ S. Penczek, Makromol. Chem. 134, 299 (1970).

${ }^{23}$ B. A. Rozenberg, V. I. Irshakh and N. S. Enikolopyan, Interchain Exchange in Polymers. (in Russian), Khimija, Moscow (1975).

${ }^{24}$ D. Z. Denney, G. Y. Chen and D. B. Denney, J. Am. Chem. Soc. 91, 6838 (1969).

${ }^{25}$ K. A. Petrov, E. Je. Nefant'ev and R. G. Galcova, Vysokomol. Soed. 6, 1545 (1964). 